\title{
A metallographic investigation of the effect of bonding pressure and surface finish on isostatic diffusion bonding of Ti-25Al-10Nb-3V-1Mo
}

\author{
Ş. $\operatorname{Talaş}^{1 *}$, T. I. Khan ${ }^{2}$ \\ ${ }^{1}$ Afyon Kocatepe University, Department of Metallurgical and Materials Engineering, A.N.S. Campus, \\ Afyonkarahisar, Turkey \\ ${ }^{2}$ University of Qatar, Dept. of Mechanical and Industrial Engineering, Doha, Qatar \\ (on leave from University of Calgary, Department of Manufacturing and Mechanical Engineering, Calgary, Canada)
}

Received 11 February 2014, received in revised form 12 May 2014, accepted 3 June 2014

\begin{abstract}
The performance of diffusion bonding is critically dependent on the surface finish and the bonding pressure holding the mating surfaces together for an appropriate time. Effects of surface finish and pressure on the bonding performance of Ti-25Al-10Nb-3V-1Mo super alpha two titanium aluminides were investigated at the temperature of $1000^{\circ} \mathrm{C}$ for $1 \mathrm{~h}$ holding time. Results showed that successful diffusion bonding was achieved using $800 \mathrm{Grit} / 15 \mathrm{MPa}$ and 180 Grit/20 MPa surface finish and pressure combinations. It was also shown that the bonding pressure and surface finish combinations used in this study affected the microstructure and the physical appearance of bond line in all specimens.
\end{abstract}

K e y w or d s: diffusion bonding, titanium aluminides, surface finish

\section{Introduction}

Titanium aluminides received considerable attention as potential materials for use in future aircraft and aerospace vehicles due to their high temperature stability, excellent strength to weight up to temperatures well above $700{ }^{\circ} \mathrm{C}$, and creep and oxidation resistance at elevated temperatures. However, their low tensile ductility and poor toughness at lower temperatures limited their use as with many aluminides [1$3]$. Alloys of interest in industry are mainly based on $\mathrm{Ti}_{3} \mathrm{Al}\left(\alpha_{2}\right)$ and $\mathrm{TiAl}(\gamma)$. One of the aluminides which were considered for such applications is Ti-25Al-10Nb$-3 \mathrm{~V}-1 \mathrm{Mo} \mathrm{Ti}_{3} \mathrm{Al}$ based super $\alpha_{2}$ titanium alloy. Super $\alpha_{2}$ phase containing titanium aluminides was developed to provide improved elevated temperature mechanical strength and environmental resistance in possibly skin and turbine replacement for heavy nickel alloys. Conventional titanium alloys are insufficient when exposed to aerodynamic heating at high speeds as a skin material for supersonic space vehicles. Therefore, Ti-25Al-10Nb-3V-1Mo
$\mathrm{Ti}_{3} \mathrm{Al}$ based super $\alpha_{2}$ titanium alloy can be a substitute for heavy nickel base superalloys for turbine application materials of conventional aircraft engines $[3,4]$. The majority of work regarding Ti-25Al-10Nb-3V-1Mo alloy concentrated on its mechanical and oxidation properties. The microstructures formed after thermomechanical processing and heat treatment regimes were found to impose a strong effect on the mechanical properties of Ti-25AI-I0Nb-3V-IMo alloy. The secondary $\alpha_{2}$ produces optimum mechanical results because of its needle-like shape [57].

Several welding techniques have been used to join similar alloys based on super $\alpha_{2}\left(\mathrm{Ti}_{3} \mathrm{Al}\right)$ titanium aluminides. In fusion welding processes, the zone that is affected by the intense heat contains undesired changes. Variations in hardness, the formation of oxides and carbides, high thermal stresses and subsequent cracks, micro-segregation in the heat-affected zone are some problems experienced in fusion welding $[8,9]$. Defect-free welds of titanium alloys have been produced using fusion welding techniques such

*Corresponding author: tel.: 902722281446; fax: 902722281447; e-mail address: stalas@aku.edu.tr 
as Electron Beam Welding (EB), Laser Welding and Gas Tungsten Arc Welding (GTAW), however, mechanical properties of the final welds are generally not satisfactory and poor ductility and weld surface cracks have been reported $[8,10,11]$. In contrast to fusion welding method, diffusion bonding can successfully be applied to Ti25Al10Nb alloys by $\mathrm{Wu}$ et al. [12]. In their work, an interlayer of $\mathrm{TiAl}_{3}$ coating and/or aluminium foil were also used to join the alloy and then followed by post bonding heat treatment that was applied to improve the bonding capacity. The diffusion bonding of Ti-25Al-10Nb3V-1Mo alloy to other alloys was also studied by Islam and Alam [13] by using microduplex IMI-325 (Ti-3Al-2.5V) and IMI318 (Ti-6Al-4V). A maximum pressure of $10 \mathrm{MPa}$ and temperature of $940^{\circ} \mathrm{C}$ for 1 hour of holding time was enough to form sound weld lines. Nevertheless, titanium alloys respond well to diffusion bonding since they present good void closure ability during diffusion bonding process due to their superplasticity property [2]. A titanium intermetallic alloy, Ti-24Al-14Nb-3V$0.5 \mathrm{Mo}$, was also diffusion bonded and its superplastic behaviour was studied in detail with an output that $\beta$ phase played a crucial role in the plastic deformation during diffusion bonding [14].

In this research, diffusion bonding of $\mathrm{Ti}-25 \mathrm{Al}-$ -10Nb-3V-1Mo super $\alpha_{2}\left(\mathrm{Ti}_{3} \mathrm{Al}\right)$ titanium aluminide was carried out with varying pressure and surface finish. Diffusion bond line was characterized by using Scanning Electron Microscope (SEM) and hardness measurements.

\section{Experimental procedure}

Ti-25Al-10Nb-3V-1Mo alloy was manufactured using vacuum arc melting method. The pieces cut from the same batch were machined to rectangular size and each surface was checked for flatness and deformation. The specimens used for metallographic examination were $25 \mathrm{~mm} \times 25 \mathrm{~mm} \times 5 \mathrm{~mm}$ pieces ground parallel on two opposite faces. The fabrication of diffusion bonds was carried out using a vacuum hot press. All specimens were slowly cooled to room temperature by $20^{\circ} \mathrm{C} \min ^{-1}$. In a previous work [15], a good bond was achieved using a combination of $1000^{\circ} \mathrm{C} / 10 \mathrm{MPa}$ for
Ta b le 1. Diffusion bonding conditions in this study

\begin{tabular}{ccc}
\hline Set & Pressure $(\mathrm{MPa})$ & Surface finish \\
\hline 1 & 15 & 180 Grit, 800 Grit, $1 \mu \mathrm{m}$ \\
2 & $15,20,30$ & 180 Grit \\
\hline
\end{tabular}

$1 \mathrm{~h}$. Based on this data a temperature of $1000^{\circ} \mathrm{C}$ and a holding time of $1 \mathrm{~h}$ were selected and pressure values of 15,20 and $30 \mathrm{MPa}$ were employed, respectively. The surface treatment is necessary before diffusion bonding to remove the surface oxides and provide a clean surface. To determine the effect of surface finish on bond line voids a surface finish of 180 Grit, 800 Grit, and a $1 \mu \mathrm{m}$ polish were used (see Table 1). For the ease of plotting the results, a Grit-to-micron conversion table [16] was referred and corresponding micron values are as follows: 180 and 800 Grit are 82 and 21 micron, respectively. For the first set of specimens (bonding pressure experiments), the opposite surfaces were ground to 180 Grit to be diffusion bonded under the condition of $1000^{\circ} \mathrm{C} / 1 \mathrm{~h}$ with varying pressures of 15, 20 and $30 \mathrm{MPa}$. This surface finish was used for bonding pressure changes because polishing to $1 \mu \mathrm{m}$ or 800 Grit finishes are not realistic for labour costs. For the second set of specimens (surface finish experiments), the opposite surfaces were ground to $180 \mathrm{Grit}$, $800 \mathrm{Grit}$, and $1 \mu \mathrm{m}$ (diamond paste) to be diffusion bonded under the condition of $1000^{\circ} \mathrm{C} / 15 \mathrm{MPa} / 1 \mathrm{~h}$.

In order to examine bond line microstructure, specimens were sectioned perpendicular to bond lines. Void lengths were measured and divided by total bond length to determine a void percentage along the bond line. For all samples, $10 \% \mathrm{HF}+40 \% \mathrm{HNO}_{3}+$ distilled water (bal.) solution was used for etching. All microhardness measurements were performed using Leitz microhardness tester and Shimadzu microhardness tester on microphases on both bonds made with different surface finishes and pressures on individual phases and up to $500 \mu \mathrm{m}$ perpendicular to bond line. Each hardness value was, at least, the average of 3 hardness test results. All samples prepared for microscopy were examined with Jeol JXA Electron Probe Microanalyzer Scanning Electron Microscope operated at $20 \mathrm{kV}$. Images were taken to show relevant microstruc-

Table 2. Results obtained from surface finish test specimens produced with combination of 15 MPa bonding pressure with changing surface finish

\begin{tabular}{ccc}
\hline Surface finish & Bond line observation & \% of linear porosity (voids) \\
\hline 180 Grit & Visible with smaller degenerated $\alpha_{2}$ grains & $\sim 10 \%$ \\
$800 \mathrm{Grit}$ & Visible with normal appearance & Less than $1 \%$ \\
$1 \mu \mathrm{m}$ & Not visible & No porosity \\
\hline
\end{tabular}


tures and voids in the bond line. The volume fractions of the phases along the bond line were calculated for the $10 \mu \mathrm{m}$ thick band on both sides of the bond line by a spot counting method using at least three SEM images taken at different magnifications. The total deformation percentage was calculated following the bonding process by simply measuring the total thickness of the specimens parallel to direction of bonding pressure before and after the experiment. Void closure behaviour or void percentage was defined as the ratio of total length of voids to total bond length along the bond line.

\section{Results and discussion}

\subsection{Surface finish tests}

The aim of this experiment was to determine the effect of surface finish on void closure across the bond line and the effect of cold worked surface layer to bond line formation. A classification of bond line morphology is made in Table 2 .

For 180 Grit specimens, the void percentage across the bond line was measured to be close to $10 \%$, which is well above a predetermined value of $1 \%$. The reason for this is that the surface asperity height and wavelength prevented the full surface contact; hence, larger bondline void size along the bond line was inevitable. Further increase in either or both pressure and holding time could reduce void size by increasing contact area. When bond line was examined at high magnification (Fig. 1a) smaller grains appeared to be $\alpha_{2}$ grains which were grouped at the interface along the bond line, being possibly a preferential phase precipitation of secondary $\alpha_{2}$ phase in retained beta matrix. Furthermore, the operation temperature is very close to the primary $\alpha_{2} \Rightarrow \beta$ phase transformation. Although this may be evaluated as dissolution of secondary $\alpha_{2}$ but the shape of these grains indicates that during cooling, secondary $\alpha_{2}$ grains may have overgrown as a result of slow cooling and high temperature solution treatment.

In contrast to 180 Grit (Fig. 1a), 800 Grit surface finished specimen produced a bond line with a few voids. In the same places, there was no apparent bond line; this shows that this surface finish is close to ideal bond conditions (Fig. 1b). For 1 micron surface finish, the bond line could not be distinguished from parent metal microstructure (Fig. 1c). This bonding seems to be ideal because there are no visible voids along the bond line; however, a secondary $\alpha_{2}$ phase had almost disappeared along the bond line at the expense of primary $\alpha_{2}$ grains in $\beta$ matrix. $\beta$ refers to the high temperature disordered b.c.c. phase found in Ti-25Al$-x \mathrm{Nb}$ system. $\mathrm{B} 2(\beta \mathrm{o})$ is the ordered derivative of the $\beta$ phase; ordering occurs near $\beta$ transus temperature.
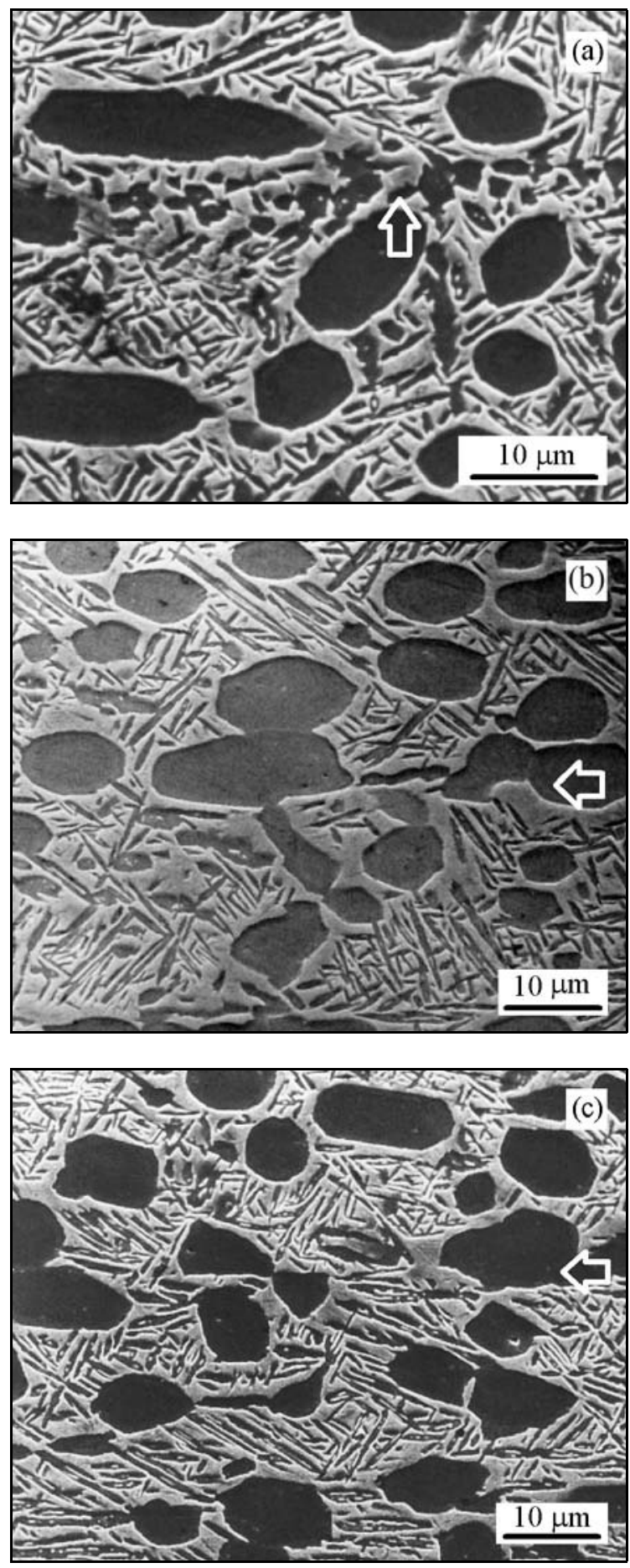

Fig. 1. Diffusion bonded specimens with 180 Grit (a), 800 Grit (b) and $1 \mu \mathrm{m}$ (c) surface finish (dark globular, dark needle-like and grey features are primary $\alpha_{2}$, secondary $\alpha_{2}$ and retained $\beta$, respectively).

Above the $\beta$ transus $\left(\sim 1060^{\circ} \mathrm{C}\right)$ single phase $\beta$ or $\mathrm{B} 2$ phase exists. Below the $\beta$ transus temperature the $\alpha_{2}$ phase is present; $\alpha_{2}$ refers to the ordered hexagonal structure of $\mathrm{Ti}_{3} \mathrm{Al}$ formed in alloys from none to somewhere less than 15 at.\% $\mathrm{Nb}[17,2,3]$. The primary $\alpha_{2}$ 
Table 3. Volume fractions of phases existing along the bond line in all specimens

\begin{tabular}{ccc}
\hline Surface finish & Secondary $\alpha_{2}+\beta$ & Primary $\alpha_{2}$ \\
\hline 180 Grit & 63.4 & 26.6 \\
800 Grit & 29.5 & 70.5 \\
$1 \mu \mathrm{m}$ & 38.3 & 61.7 \\
\hline
\end{tabular}

phase is stable until $1060^{\circ} \mathrm{C}$ but at this temperature, this phase does not go into solution unlike secondary $\alpha_{2}$ and during slow cooling, $\beta$ phase does not transform to secondary $\alpha_{2}$ completely which is diffusion controlled process requiring time to complete transformation $[18,19]$. Atomic flux through $\alpha_{2} / \beta$ interface appears to be not enough to complete $\beta$ transformation to secondary $\alpha_{2}$, which is merely related to operating temperature and solubility effects [17]. Having a rich content of $\mathrm{Al}, \alpha_{2}$ also contains some $\mathrm{Nb}$ due to the stabilizing effect from $\mathrm{V}$ and Mo additions. However, it also needs the influx of $\mathrm{V}$ and Mo in the presence of high amount of $\mathrm{Al}$ to supersature $\alpha_{2}$ in order to transform to $\beta$ phase, which is prevented due to the low solubility of $\mathrm{Nb}[18,19]$. It is observed that the volume fraction, and hence the area of secondary $\alpha_{2}+\beta$ matrix is in increase as the surface roughness increases (Table 3). If it is considered that deformed layers may help to form fresh grains at appropriate temperatures such as one third of melting temperature, it can be said that the highly deformed layer has re-crystallized on both sides of the bond line with the same crystallographic preference as the matrix. In later steps of bonding, these grains may be eventually transformed to $\beta$ before the precipitation of secondary $\alpha_{2}$ occurred.

An ideal bond line was obtained with $1 \mu \mathrm{m}$ surface finish since there was no important change in microstructure and secondary $\alpha_{2}$ grains did not completely disappear in transformed $\beta$ matrix (Fig. 1c). However, because of the fine surface finish, very close surface to surface contact and no voids along the bond line were observed. But in some regions the shape of $\alpha_{2}$ grains are uneven and primary $\alpha_{2}$ grains are overgrown along the bond line; this can be attributed to an emerging effect of secondary $\alpha_{2}$ grains between primary $\alpha_{2}$ grains. The $\beta$ phase was still dominant phase along the bond line.

The mechanical properties of materials are strongly related to the microstructure, i.e. the shape of the primary $\alpha_{2}$ and spatial distribution of secondary $\alpha_{2}$ phase. Secondary $\alpha_{2}$ is very important for tensile strength and creep performance because the structure consists of needle-like secondary $\alpha_{2}$, which is harder than $\beta$ matrix. A microstructure consisting of colonies formed by $\alpha_{2}$ platelets can result in a high fracture toughness, high crack propagation resistance
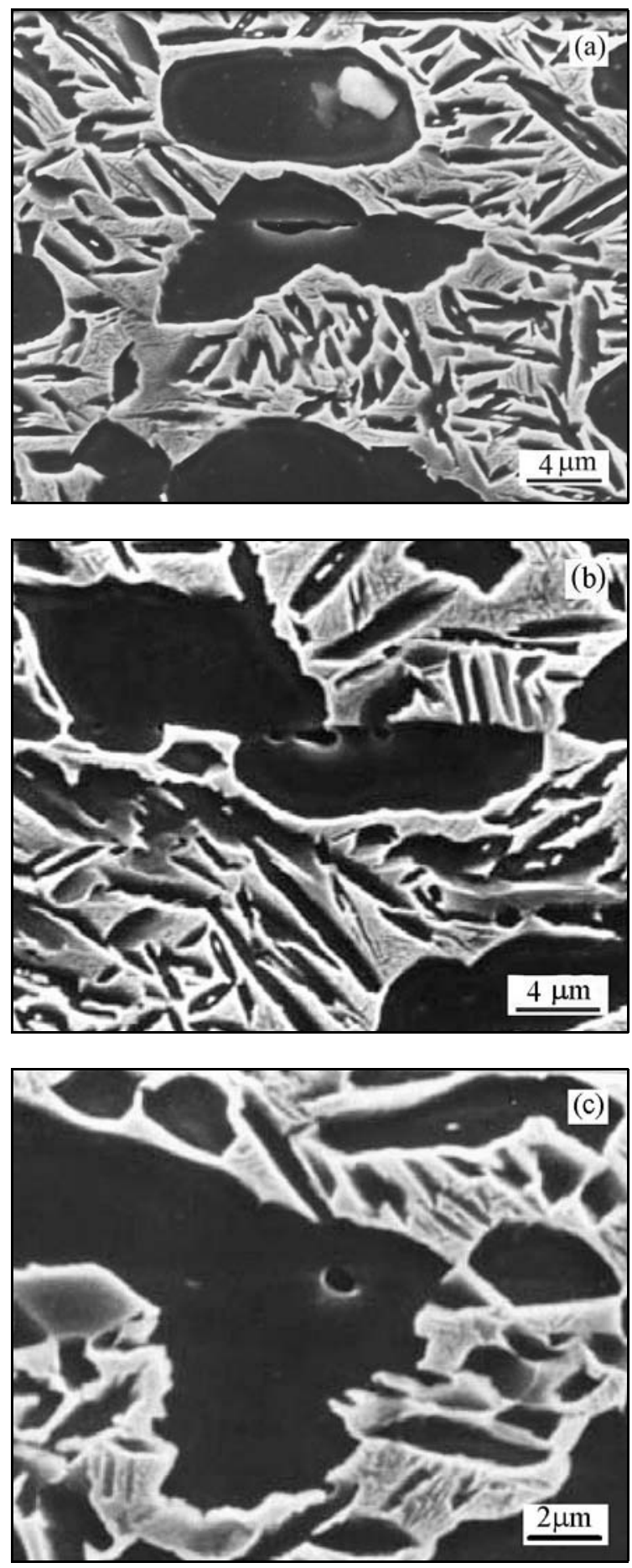

Fig. 2. Bond line voids observed in diffusion bonded specimens $15 \mathrm{MPa}$ (a), $20 \mathrm{MPa}$ (b) and $30 \mathrm{MPa}$ (c).

and superior creep strength when compared to the duplex microstructure consisting of lamellar colonies and single phase gamma grains [20]. When secondary alpha-two goes into solution, lower tensile and creep strength should be expected. In this work the effect of surface finish on bonding behaviour agrees with earlier works $[19,20]$. 


\subsection{Pressure}

The bond line images of specimens bonded at various pressures with 180 Grit surface finish are shown in Fig. 2. When the specimen bonded at $15 \mathrm{MPa} / 180$ Grit was examined, smaller secondary $\alpha_{2}$ grains and primary $\alpha_{2}$ grains along the bond line were observed (Fig. 2a). In $20 \mathrm{MPa} / 180$ Grit specimen, however, a void size decreased dramatically and hence the bond line and the appearance of bond were very good (Fig. 2b). On $30 \mathrm{MPa} / 180$ Grit bond line, smaller secondary $\alpha_{2}$ grains and overgrown primary $\alpha_{2}$ grains were shown to be located near bond line (Fig. 2c); there is no apparent bond line feature.

In diffusion bonding, void closure is the main objective of the process. This is directly affected by the amount of pressure applied as some of process parameters during bonding will be active, such as superplasticity and deformation of asperities. As the pressure increases the void shape varies but interestingly after a certain length of time the void closure will be determined by diffusion and grain growth mechanisms. As seen in Fig. 2 the void shape becomes smaller and more cylindrical as the bonding pressure increases. This observation agrees with the modelling of void closure proposed by Hill and Wallach [22] and investigated by Allen and White [23]. This indicates that the process is time dependent, in other terms, it is a diffusion controlled after the destruction of surface asperities. The possible mechanism accounted for at this stage may be surface source mechanism. At the beginning of bonding process, the main diffusion mechanisms may be interface and bulk deformation mechanisms which are supposed to be fast and effective in eliminating the large voids.

At higher temperatures some materials show superplastic behaviour during isostatic diffusion bonding in titanium aluminides, super $\alpha_{2}$ [24, 25]. The same authors $[24,25]$ found that as the surface roughness increases the contribution of superplasticity feature to bonding also increases. In contrast to this, as the roughness decreases (1200 Grit, finer polishing, etc.) other mechanisms (interfacial diffusion) become more effective in bonding. However, bonding capacity is not directly related to superplasticity, it just accelerates the formation of bond across the interface. This feature is mainly dependent on the grain size; the fine grained materials are more suitable for superplasticity as the creep mechanism is readily achieved. This contributes to bonding formation [26]. Although, dynamic grain growth was reported during superplastic deformation of the super $\alpha_{2}$ alloy at $980^{\circ} \mathrm{C}$ [27]. In the same work, when the temperature of deformation was increased up to $1050^{\circ} \mathrm{C}$, additional transformations were observed and dynamic grain growth took place, leading to the formation of nodules of $\alpha_{2}$ phase with the size

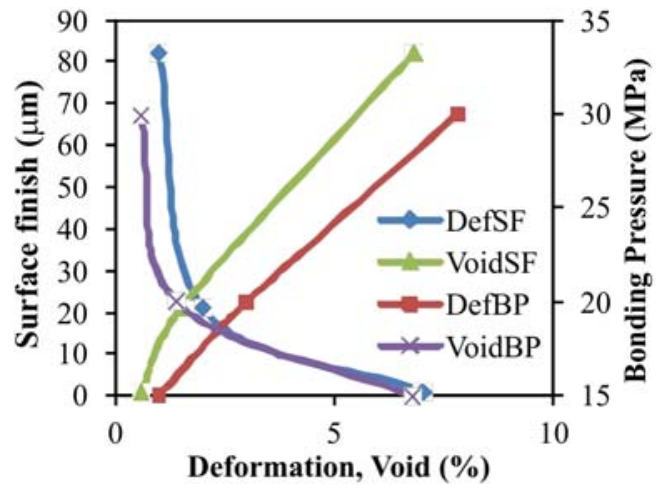

Fig. 3. The effect of bonding pressure and surface finish on total deformation and void closure behaviour (deformation (DefSF) and void (voidSF) percentages with respect to surface finish; deformation (DefBP) and void (void BP) percentages with respect to bonding pressure; 180 and 800 Grit were taken as 82 and 22 microns, respectively [16]).

larger than $10 \mu \mathrm{m}$. This may be the case in this study.

\subsection{Microhardness, deformation and void measurement results}

In Fig. 3, total deformation percentage, bonding pressure, void closure behaviour, i.e. void length fraction and surface finish values are given. When the bond lines are examined the percentage of voids in $15 \mathrm{MPa}$ bond line was more than $6 \%$, in other bond lines, it was less than $1 \%$. This shows that $20 \mathrm{MPa}$ bond pressure may produce a better bond performance. Indeed, when the $20 \mathrm{MPa}$ bond line is examined, it can be seen that there are no distinct changes in microstructure (Fig. 2b). Although a pressure of 30 MPa produced a good bond but the total deformation was higher than $7 \%$ which is well above the set value. Similar results were also obtained for surface finish experiments with a difference of slightly lower void percentages.

Hardness test on microphases showed that $\alpha_{2}$ phase had higher hardness value than that of beta matrix microphase, $413 \mathrm{HV}$ and $370 \mathrm{HV}$, respectively. The results of hardness tests carried out perpendicular to bond line on specimens with a 180 Grit surface finish and different pressures are shown in Fig. 4a.

Hardness values for 180 and 800 Grit and $1 \mu \mathrm{m}$ polished surface finish specimens (Fig. 4b) revealed that there was little difference between hardness results taken from both ends, and at the bond line, therefore, it can be concluded that microhardness results gave no important indication of distinctive hardness changes measured perpendicular to bond lines for joints made with different surface finish. For specimens bonded at different pressures microhardness test results gave an indication of slight hardness gradient measured per- 

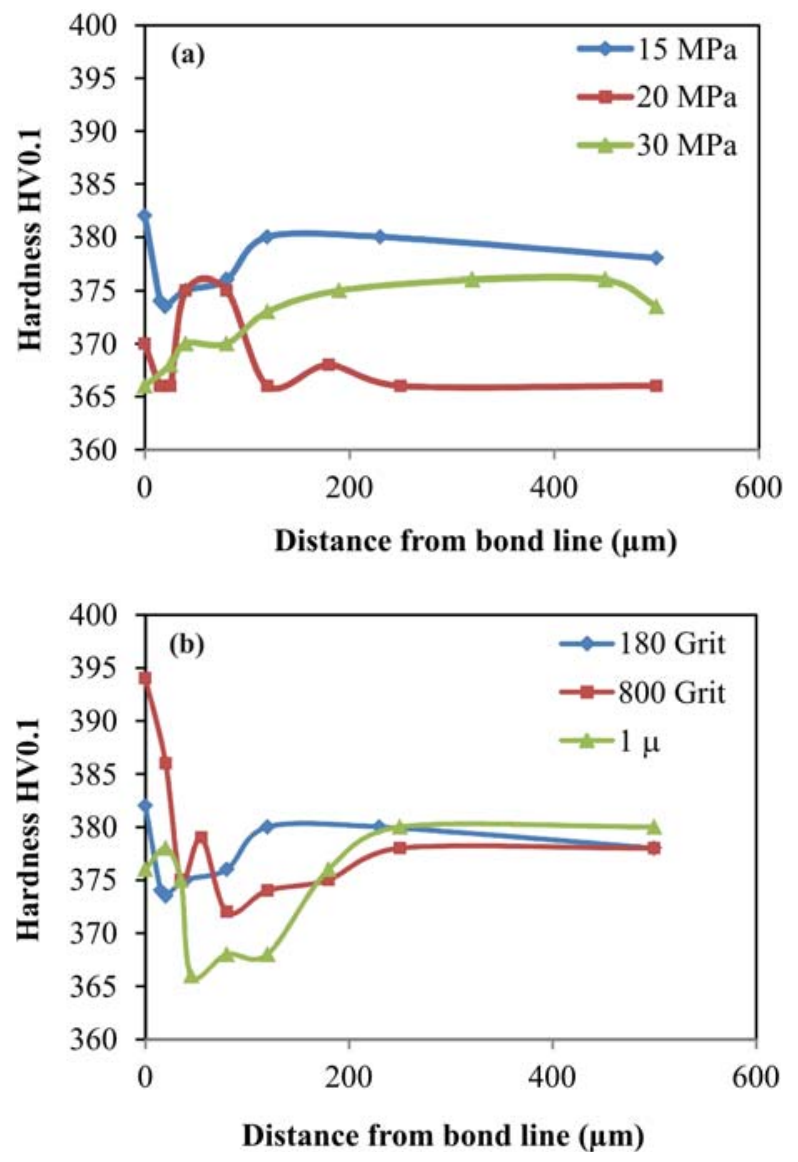

Fig. 4. Hardness measurements with respect to distance from bond line in specimens with 180 Grit surface finish at varying bonding pressure (a) and $15 \mathrm{MPa}$ bonding pressure at varying surface finish (b).

pendicular to a bond line. Changes in hardness measurements suggest that harder microphases such as primary and secondary $\alpha_{2}$ phases are in growth along the bond line of joints, existing in smaller size but high in number. Such an increase in volume fraction of harder microphases is probably a result of transformation of $\beta$ matrix to secondary $\alpha_{2}$ along the bond line. This process may be triggered by the deformation that is created by plastic flow and creep of surface asperities. The increase in plastic flow will probably accelerate the formation of more diffusion paths created during the joining process assisted by the breakdown of primary $\alpha_{2}$ grains along the bond line into smaller primary $\alpha_{2}$ grains. Having a smaller volume and hence lower surface free energy, these particles begin to transform to $\beta$ by diffusion mechanism. For very small particles the dissociation by diffusion is easily achieved since the bonding temperature is very close to $\alpha_{2}-\beta$ temperature. On cooling the transformation is halted or secondary $\alpha_{2}$ precipitates back from $\beta$ matrix phase. Lower bonding pressures may result in smaller particles created by the breakdown of harder primary $\alpha_{2}$ grains and hence easily decomposes to $\beta$, which is softer. This process may be effective in first $100 \mu \mathrm{m}$ of the joint thickness as suggested by hardness results in Fig. 4. Hardness values at bond lines of specimens bonded at $15 \mathrm{MPa}$ and $20 \mathrm{MPa}$ pressures are probably due to the presence of fine precipitates of secondary $\alpha_{2}$.

\section{Conclusions}

Ti-25Al-10Nb-3V-1Mo alloy was diffusion bonded and effects of surface finish and pressure in diffusion bonding were observed and a comparison was made with some earlier works. Following findings can be concluded from this study:

1. The specimen bonded under $15 \mathrm{MPa}$ pressure $/ 1 \mu \mathrm{m}$ surface finish combination provided an ideal bond line.

2. This work has shown that $15 \mathrm{MPa} / 800 \mathrm{Grit}$ and $20 \mathrm{MPa} / 180$ Grit combinations produce good bond line.

3. The bonding temperature of $1000^{\circ} \mathrm{C}$ appears to be still high because of the high transformed $\beta$ percentage $(\sim 63 \%)$ and the formation of secondary alpha two laths.

4. The secondary $\alpha_{2}$ formation in microstructure is not similar to that found in parent metal, which is important for high temperature creep strength.

\section{Acknowledgement}

Financial support from the Ministry of National Education of Turkey is acknowledged.

\section{References}

[1] Stoloff, N. S., Liu, C. T, Deevi, S.: Intermetallics, 8 , 2000, p. 1313. doi:10.1016/S0966-9795(00)00077-7

[2] Kumpfert, J., Leyens, C.: Titanium and Titanium Alloys: Fundamentals and Applications. Eds.: Leyens, I., Peters, M. Weinheim, Wiley-VCH Verlag GmbH \& Co. KGaA 2003.

[3] Ward, C. H.: Int. Mater. Rev., 38, 1983, p. 79. doi:10.1179/imr.1993.38.2.79

[4] Banerjee, D.: Intermetallic Compounds. Eds.: Westbrook, J. H., Fleischer, R. L. New York, Wiley and Sons 1989.

[5] Rajendra, U. V., Park, Y. S., Zhe, J., Gray, G. T., Butt, D. P.: Oxid. Met., 50, 1998, p. 215. doi:10.1023/A:1018836304374

[6] Huang, C., Dean, T. A., Loretto, M. H.: Mater. Sci. Tech., 11, 1995, p. 143. doi:10.1179/mst.1995.11.2.143

[7] Fu, H. C., Huang, J. C, Wang, T. D., Bampton, C. C.: Acta Mater, 46, 1998, p. 465. doi:10.1016/S1359-6454(97)00278-4

[8] Patterson, R. A., Martin, P. L., Damkroger, B. K.: Weld. J., 69 (1) 1990, p. 39. 
[9] Wunderlich, W., Frommeyer, G., Czarnowski, P.: Mater. Sci. Eng. A, 164, 1993, p. 421. doi:10.1016/0921-5093(93)90705-J

[10] Mullins, F. D., Becker, D. W.: Weld. J., 59, 1980, p. 177.

[11] Bartle, P. M.: Weld. J., 54, 1975, p. 799.

[12] Wu, Y. T., Wei, W. S., Koo, C. H.: Sci. Technol. Weld. Joi., 3, 1998, p. 97. doi:10.1179/stw.1998.3.2.97

[13] Islam, M. F., Alam, M. O.: In: Proceedings of Titanium: Extraction and Processing. Eds.: Mishra, B., Kipouros, G. J. Indianapolis, Minerals Met \& Mat Soc. 1997, p. 175.

[14] Zhu, H. L., Li, Z. Q., Wang, C. X.: Mater. Sci. Forum, 357, 2001, p. 607. doi:10.4028/www.scientific.net/MSF.357-359.607

[15] Mears, S. J.: MSc Thesis, Faculty of Engineering, Brunel University, 1996, p. 22.

[16] http://dnn.fepa-abrasives.org/Abrasiveproducts/ Grains/Pgritsizescoated.aspx

[17] Semiatin, S. L., Knisley, S. L., Fagin, P. N., Zhang, F., Barker, D. R.: Metall. Mater. Trans. A, 34, 2003, p. 2377. doi:10.1007/s11661-003-0300-0

[18] Peters, J. A., Bassi, C.: Scripta Metall. Mater., 24, 1990, p. 915. doi:10.1016/0956-716X(90)90137-6
[19] Khadzhieva, O. G., Illarionov, A. G., Popov, A. A.: Phys. Met. Metallogr., 115, 2014, p. 12. doi:10.1134/S0031918X14010098

[20] Huan, C., Dean, T. A., Loretto, M. H.: Mater. Sci. Eng. A, 191, 1995, p. 39. doi:10.1016/0921-5093(94)09624-6

[21] Chen, Z., Simca, F., Cope, M. T.: Mater. Sci. Tech., 8, 1992, p. 729. doi:10.1179/mst.1992.8.8.729

[22] Hill, A., Wallach, E. R.: Acta Metall., 37, 1989, p. 2425. doi:10.1016/0001-6160(89)90040-0

[23] Allen, D. J., White, A. A. L.: In: Proceedings of The Joining of Metal: Practice and Performance. Warwick, Institute of Metallurgy 1981, p. 96.

[24] Pilling, J., Ridley, N., Islam, M. F.: Mater. Sci. Eng. A, 205, 1996, p. 72. doi:10.1016/0921-5093(95)09871-2

[25] Somekawa, H., Higash, K.: Mater. Trans., 44, 2003, p. 1640. doi:10.2320/matertrans. 44.1640

[26] Maehara, Y., Komizo, Y., Langdon, T. G.: Mater. Sci. Tech., 4, 1988, p. 669. doi:10.1179/mst.1988.4.8.669

[27] Jobart, D., Blandin, J. J.: Mater. Sci. Eng. A, 207, 1996, p. 170. doi:10.1016/0921-5093(95)10037-7 